\title{
CDC Occupational HIV Surveillance System
}

The Centers for Disease Control (CDC) has initiated a nationwide surveillance system for human immunodeficiency virus (HIV)infected persons for whom healthcare occupational exposure may be the mode of HIV transmission. The objective is to quantify the number of persons infected with HIV due to occupational exposure and to identify the incidents that result in transmission. The information will be used to develop recommendations and prevention measures to prevent future occurrences. The CDC encourages hospital epidemiologists to report suspected cases.

\section{WHO SHOULD BE}

RE P O R TE D

HIV-infected healthcare or public safety workers who may have been infected from an occupational HIV exposure.

\section{HOW TO REPORT}

Hospital epidemiologists and other healthcare providers (including employee health physicians or infection control practitioners) should contact the state or local health department personnel responsible for HIV/acquired immunodeficiency syndrome (AIDS) case surveillance. Alternatively, the infected healthcare worker can contact the health department directly. With the worker's consent, the HIV/AIDS surveillance staff will interview the worker and review medical/ employment records to collect information on the healthcare worker's occupational exposures, nonoccupational HIV risk factors, results of previous HIV tests, and the HIV status or risk factor information on the source patient.

Health departments then forward the reports to the CDC. To protect confidentiality, no names or other identifying information on the healthcare worker are sent to the CDC. Questions regarding reporting procedures should be directed to the HIV/AIDS surveillance staff in the state or local health department, or the Division of HIV/AIDS, MS E-46, CDC, 1600 Clifton Road, Atlanta, GA 30333; telephone (404) 6392070.

Reports of information collected in this system, as well as AIDS case surveillance, are included in the CDC's quarterly "HIV/AIDS Surveillance Report."

\section{Fellowship in Hospital Epidemiology}

Applications are being accepted for a fellowship in hospital epidemiology at the College of Medicine, University of Tennessee, Memphis, for July 1, 1993. The program includes training in biostatistics, hospital epidemiology, infection control, outbreak investigation, use of computers in hospital epidemiology, and hospital epidemiology research. Fellows will conduct one or two prospective epidemiologic studies during the fellowship. Funds are provided for books, journals, and travel to scientific meetings. Candidates should hold an MD degree and have at least three years of postgraduate training in a medical specialty.

For more information about the fellowship contact Dr. C. Glen Mayhall, Division of Infectious Diseases, University of Tennessee, Memphis, 956 Court Ave., Room H308, Memphis, TN 38163; telephone (901) 5285730.

\section{SHEA Goodnight Gracie}

With this issue of Infection Control and Hospital Epidemiology, I finish a five-year term as the editor of the SHEA News. Beginning with the January 1993 issue, the SHEA News editor will be Dr. C. Glen Mayhall. I have enjoyed being able to serve SHEA and the SHEA members and wish Dr. Mayhall the best of luck.

Robert A. Weinstein Chicago, Illinois 


\section{The Third Annual Meeting of}

Strig

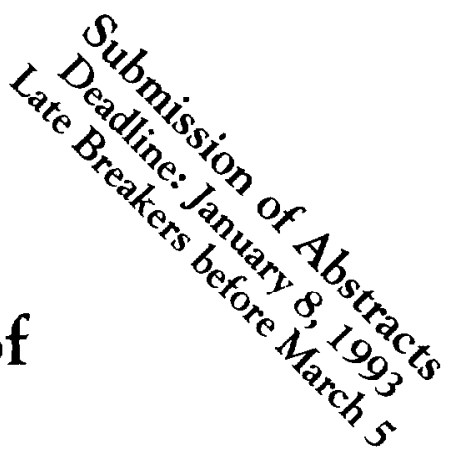

The Society for

Hospital Epidemiology

of America

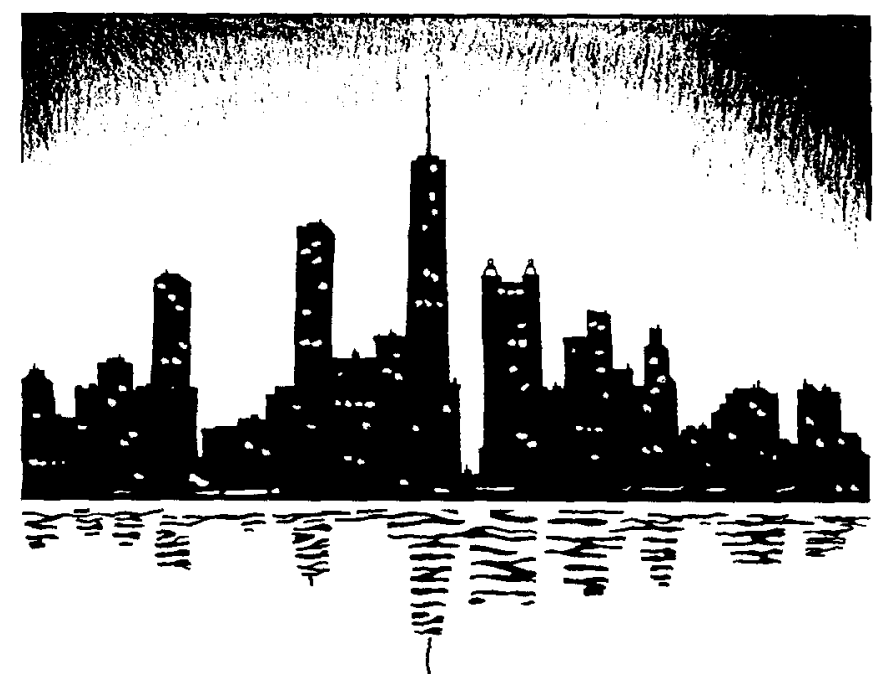

\section{April 18-20, 1993 \\ The Palmer House Hotel, Chicago, Illinois}

\section{5 hours of Category 1/AMA Credit}

For Preliminary Program and Registration Information, please contact SHEA at 609-845-1720 or fax 609-853-0411

University of Illinois College of Medicne is accredited by the Accreditation Council for CME to sponsor continuing medical education for physicians. University of Illinois College of Medicine designates this continuing medical education activity for 15 credit hours in Category 1 of Physicians Recognition A ward of the American M edical Association. 